\title{
O processo de (re) orientação teórico-epistemológica do departamento III - FACED/UFBA (2004-2006)
}

Vamberto Ferreira Miranda

Mestre em Educação pela UFBA e professor da UNEB

\section{Resumo}

Buscamos analisar de um ponto de vista epistemológico (Habermas) três teses produzidas recentemente pelo Departamento de Educação III FACED/UFBA que têm como objeto de estudo a capoeira. A metodologia do estudo foi de natureza qualitativa, destacando elementos da racionalidade diferenciada para pesquisa e produção do conhecimento na educação física presente nestas teses. Os resultados apontaram alguns indicadores duma (re) orientação teórico-epistemológica no campo acadêmico da educação física no estado da Bahia, a partir do diálogo com formas de manifestação da cultura corporal dos povos afro-descendentes.

Palavras-Chave: Epistemologia; Produção do Conhecimento; Capoeira.

\begin{abstract}
This research aimed at analizing three doctorate theses from the Department of Education III - FACED/UFBA which have as study object the capoeira. The theoretical reference used here was related to pressupositions of Habermas's epistemology. The methodology of the study was one of qualitative nature. The results indicated pointers of a possible theoretical-methodological reorientation in the field of Physical Education in the state of Bahia, from the necessities of the social and cultural contexts in the contemporary society, mainly of Africandescendent peoples.
\end{abstract}

Keywords: Production of the Knowledge; Physical Education; Capoeira. 
$\mathrm{O}$ presente estudo trata da análise de três teses produzidas recentemente, referentes ao período de 2004-2006, investigando formas de manifestação da cultura corporal dos povos afrodescendentes no estado da Bahia, em particular o fenômeno da capoeira, apontando uma perspectiva diferenciada para a pesquisa e produção do conhecimento no campo da educação física, a partir do diálogo com as tradições destes povos. Essa constatação motivou um "balanço crítico" sobre este conhecimento.

\section{Epistemologia}

Jüngen Habermas (1982), um dos pensadores integrantes da chamada "Escola de Frankfurt", em sua obra clássica Erkenntnis und Interesse, apresentou como tese central em sua investigação que todo conhecimento é posto em movimento por interesses que o orientam, dirigem-no, comandamno.

Ao discorrer acerca das três categorias do quadro metodológico do processo de pesquisa nas ciências, este autor (s.d., p. 136-137) defendeu a idéia de que é possível definir uma conexão específica entre "regras lógicomatemáticas" e "interesses" (motivações) como guia do conhecimento.

Para as três categorias de processos de investigação pode demonstrar-se uma conexão específica de regras lógico-metódicas e o interesse que guiam o conhecimento. Tal é a tarefa de uma teoria crítica da ciência que se esquiva das ciladas do positivismo. No exercício das ciências empírico-analíticas, imiscui-se um interesse técnico do conhecimento; no exercício das ciências histórico-hermenêuticas, intervém um interesse prático do conhecimento, e, no posicionamento das ciências de orientação crítica, está implicado aquele interesse emancipatório do conhecimento, que [...] estava subjacente, de um modo inconfessado, às teorias tradicionais ${ }^{1}$ (Habermas, 1982).

Estes pressupostos sobre o discurso epistemológico apresentados inicialmente por Habermas foram aprofundados aqui no Brasil por alguns

\footnotetext{
${ }^{1}$ No prefácio de 1968, da obra Conhecimento e interesse, Habermas (1982) esclarece que estes critérios sistemáticos que orientam a pesquisa foram expostos, pela primeira vez, na aula inaugural que ministrou na Universidade de Frankfurt, em 1965.
} 
autores que se dedicaram ao desenvolvimento do que tem sido denominada em nível das teorias do conhecimento de epistemologia dialética.

Nesse sentido, Sánchez Gamboa (1987, p.16) destacou alguns elementos fundamentais para a compreensão desta perspectiva epistemológica. Nas palavras deste autor,

A epistemologia dialética como Teoria do Conhecimento se desenvolve na relação crítico-operativa entre Filosofia e Ciência, não se fecha no campo da Ciência tal como ocorre no positivismo. Torna-se Crítica do Conhecimento na medida em que utiliza as leis e categorias da dialética materialista como instrumental crítico-reflexivo, para estudar os processos da produção científica, entendidos como processos de conhecimento humano. Nesse sentido, a Filosofia resgata sua posição frente à Ciência enquanto crítica do conhecimento científico [...].

Em nosso entendimento esta perspectiva epistemológica de crítica à produção científica teve uma incursão muito significativa, nas últimas décadas, no campo da educação física. Por isso, analisaremos esta questão mais de perto.

\section{Epistemologia e educação física}

O debate em torno das tendências do conhecimento, no campo da educação física, tem sido aprofundado, sobretudo, a partir da análise da produção científica em nível epistemológico. Vários (as) autores (as) têm se dedicado a este tema, nos últimos anos ${ }^{2}$. Para fins deste estudo destacamos alguns destes trabalhos.

Souza e Silva (1997) analisou, a partir das abordagens metodológicas, as implicações epistemológicas das dissertações, desenvolvidas nos cursos de Mestrado em Educação Física e Esportes da USP, UFSM, UFRJ, Unicamp, UFRGS e UFMG, durante o período de 1988 a 1994, levando em

\footnotetext{
${ }^{2}$ Desde o ano de 1995, foi constituído o Grupo de Trabalho Temático (GTT) permanente de Epistemologia do Colégio Brasileiro de Ciências do Esporte (CBCE). No XV Congresso Brasileiro de Ciências do esporte (CONBRACE) e II Congresso Internacional de Ciências do Esporte (CONICE), realizado em Recife-PE (2007) foram apresentadas 29 comunicações, divididas em nove mesas temáticas; uma sessão de pôsteres; e uma mesa especial com o título: Giros epistemológicos em Educação Física/Ciências do Esporte. Cf.: Livro de resumos e programação. XV Congresso Brasileiro de Ciências do Esporte [e] II Congresso Internacional de Ciências do Esporte, 16 a 21 de set. de 2007. Recife: EDUPE, 2007.
} 
consideração suas inter-relações com os determinantes sócio/econômico/políticos.

Bracht (1999) partindo da consideração de que o debate em torno da neutralidade do conhecimento científico foi superado discutiu a relação entre o conhecimento e a política (a democracia), delineando algumas posições presentes na educação física brasileira e, em particular, no Colégio Brasileiro de Ciências do Esporte (CBCE).

Fernsterseifer (1999) buscou, partindo do pressuposto de que a crise pela qual passa nossa cultura produz e é resultado de uma crise que atinge também a educação e, em particular, a educação física, construir saídas, a partir de uma profunda investigação do caráter desta crise e das perspectivas de análise/superação da mesma.

Sánchez Gamboa et al (2007) apresentaram um balanço crítico da pesquisa em educação física, no nordeste do Brasil, produzida por pesquisadores que atuam nos estados de Alagoas, Bahia, Pernambuco e Sergipe, no período de 1982 a 2004; seus resultados apontaram para a massa crítica e o potencial humano para a criação de programas de pós-graduação na região ${ }^{3}$.

Em síntese, compreendemos que há um predomínio dos pressupostos Habermasianos, ou da "teoria crítica do conhecimento"4 nas análises desenvolvidas por estes autores (as), nestes trabalhos. Consideramos de

\footnotetext{
3 As referências utilizadas, aqui, são aquelas que fizeram parte dos dois primeiros "Seminários de Epistemologia e Teorias da Educação", realizados pelo grupo PAIDÉIA, da Faculdade de Educação, da Universidade Estadual de Campinas (Unicamp), nos anos de 2005 e 2006. Estes pesquisadores (as) parecem representar aqueles que mais avançaram na produção acerca da epistemologia da educação física a partir dos pressupostos habermasiano.
}

${ }^{4}$ Raymond Geuss (1988) apresenta três teses acerca dos traços distintivos essenciais de uma "teoria crítica":

1. Teorias críticas têm posição especial como guias para a ação humana, visto que:

a) Elas visam produzir esclarecimento entre os agentes que as defendem, isto é, capacitando esses agentes a estipular quais são seus verdadeiros interesses.

b) Elas são inerentemente emancipatórias, isto é, elas libertam os agentes de um tipo de coerção que é, pelo menos parcialmente, auto-estima, a auto-frustração da ação humana consciente.

2. Teorias críticas têm conteúdo cognitivo, isto é, são formas de conhecimento.

3. Teorias críticas diferem epistemologicamente de teorias em ciências naturais, de maneira essencial. As teorias em ciência natural são "objetificantes"; as teorias críticas são "reflexivas". 
extrema relevância tais análises para a área, pois indubitavelmente alinhamse com os projetos históricos de emancipação humana.

Entretanto, não tínhamos conhecimento de investigações sobre as teses produzidas pelo Departamento de Educação III/FACED/UFBA, bem como, sobre a problemática da produção científica referendada na cultura corporal dos povos afro-descendentes, justificando o nosso foco investigativo.

Nesse sentido, apresentaremos na sequiência, um pouco do percurso deste Departamento, de onde provém o discurso dos autores das teses analisadas, a fim de localizar o objeto estudado.

\section{O departamento de educação III/FACED/UFBA}

Segundo Ferraro (1991) a educação física foi implantada na UFBA, em 1977. Por meio da aprovação do parecer de 16 de agosto de 1977, no Conselho Universitário, foi criado o Departamento de Educação Física, alocado na Superintendência Estudantil da UFBA.

A transferência do Departamento de Educação Física da Superintendência Estudantil para a Faculdade de Educação (FACED) ocorreu mediante aprovação da Congregação desta unidade e do Conselho Universitário da "proposta de alteração parcial do regimento da FACED", a qual incluiu o Departamento de Educação III (educação física) e as disciplinas do novo departamento na FACED, em 1985.

Através do parecer $n^{\circ} .425 / 87$, de 16 de junho de 1987, da Câmara de Ensino e Graduação foi aprovado o curso de Licenciatura em Educação Física da Universidade Federal da Bahia. Em conseqüência disso, em 25 de setembro de 1987, foi instalado na FACED oficialmente o colegiado do curso de Educação Física.

Rosso (2007) destaca que em 1996 o referido curso foi reconhecido pelo Conselho Federal da Educação e a partir de 2000 vem sendo submetido à avaliação interna e a debates para a sua reestruturação. Porém, segundo esta autora, o curso carece de uma infra-estrutura adequada para o seu desenvolvimento. 
Atualmente o Departamento de Educação Física continua vinculado à Faculdade de Educação da UFBA, tendo 17 professores $^{5}$ na composição de seu corpo docente.

Nos limites deste estudo delimitamos como objeto as teses produzidas por este corpo docente, entendendo-as como a produção científica fruto de um processo de pesquisa que articula uma problemática mais profunda no campo da educação física.

\section{A produção do conhecimento sobre a cultura corporal afro-descendente}

Dentre as dez teses defendidas pelos professores - pesquisadores do Departamento de Educação III/FACED/UFBA ${ }^{6}$, no período de 1993 a

\footnotetext{
${ }^{5}$ À época da pesquisa estes eram os professores: Admilson Santos, Amélia Vitória Souza Conrado, Carlos Roberto Colavolpe, Celi Nelza Zulke Taffarel, Claudia Miranda Souza, Cláudio de Lira Santos Junior, Coriolano Pereira da Rocha Jr., Fernando Reis do Espírito Santo, Francisco José Gondim Pitanga, Helio Jose Bastos C. Campos, José Ney do Nascimento Santos (Chefe do Departamento), Maria Cecília de Paula Silva, Maria Elisa Lemos Cunha, Nair Casagrande, Orlando José Hage de Santana, Pedro Rodolpho J. Abib, Romilson Augusto dos Santos.
}

${ }^{6}$ As teses foram às seguintes: a) ABIB, Pedro Rodolpho Jungers. Capoeira angola: cultura popular e o jogo dos saberes na roda. Campinas, 2004, tese (doutorado em ciências sociais aplicadas à educação). Universidade Estadual de Campinas; b) CAMPOS, Hélio José Bastos Carneiro de. Capoeira regional: a escola de Mestre Bimba. Salvador, 2006, tese (doutorado). Faculdade de Educação, Universidade Federal da Bahia; c) CONRADO, Amélia Vitória de Souza. Capoeira angola e dança afro: contribuições para uma política de educação multicultural na Bahia. Salvador, 2006, tese (doutorado em educação) Faculdade de educação, Universidade Federal da Bahia; d) PAULA SILVA, Maria Cecília de. Da educação física, moral e intelectual a um corpo idealizado: desvelando o discurso médico nas teses da Faculdade de Medicina do Rio de Janeiro, 2002 (Tese de Doutorado): Programa de Pós Graduação em Educação Física, Universidade Gama Filho; e) PITANGA, Francisco José Gondim. Análise da associação e poder discriminatório do índice de conicidade e outros indicadores antropométricos de obesidade com risco coronariano em adultos na Cidade de Salvador. Salvador, 2004, tese (Doutorado). Instituto de Saúde Coletiva-ISC, Universidade Federal da Bahia; f) SANTO, Fernando Reis do Espírito. Políticas de reformulação curricular e a formação em Educação Física no Brasil. São Paulo, 2004, tese (Doutorado em Educação). Pontifícia Universidade católica de São Paulo; g) SANTOS, Admilson. Representação social de esportes sob a ótica de pessoas cegas. Salvador, 2004, tese (doutorado em educação) Faculdade de educação, Universidade Federal da Bahia; h) SANTOS JÚNIOR, Cláudio de Lira. A formação de professores de educação física: a mediação dos parâmetros teórico metodológicos. Salvador, 2005, tese (doutorado em educação) Faculdade de educação, Universidade Federal da Bahia; i) SOUZA, Claudia Miranda. Atividade física esportiva em espaço público: uma abordagem etnográfica em saúde. Salvador, 2003, tese (Doutorado em Saúde Pública). Instituto de Saúde Coletiva, Universidade Federal da Bahia; j) TAFFAREL, C. A formação profissional da educação: o processo de trabalho pedagógico e trato com o conhecimento no curso de Educação Física. Campinas, 1993, tese (Doutorado em Educação) - Faculdade de Educação, Universidade Estadual de Campinas. 
$2006^{7}$, verificamos que três delas, produzidas recentemente, tratavam do fenômeno da capoeirar, a saber: Abib (2004), Conrado (2006) e Campos (2006).

Compreendemos a capoeira enquanto expressão destacada das formas de manifestação da cultura corporal dos povos afro-descendentes, de maneira que nos dedicamos à análise de alguns pressupostos contidos nestas teses buscando reconhecer possibilidades de uma abordagem mais contextualizada para a pesquisa e para a produção do conhecimento no campo da educação física no estado da Bahia.

De posse das três teses citadas anteriormente iniciamos a leitura e análise destas, visando apreender fundamentos metodológicos e epistemológicos do processo de pesquisa que toma como referência a cultura corporal no estado da Bahia.

Nesse sentido, os problemas de pesquisa definidos por estes pesquisadores oriundos do campo acadêmico da educação física, em suas teses de doutoramento, podem ser indicadores desta possível reorientação epistemológica, a partir dos trabalhos interdisciplinares, tendo como ponto de partida às demandas do contexto sócio-cultural da sociedade contemporânea, quais sejam:

[...] a necessidade de constituição de uma nova racionalidade que seja capaz de interpretar e validar os saberes ocultos e silenciados, presentes no universo da cultura popular, como forma de ampliação das possibilidades de um diálogo frutífero entre os saberes provenientes das várias tradições, presentes tanto no âmbito da academia quanto no da cultura popular, sem hierarquias e discriminações (Abib, 2004, Resumo).

[...] como os conteúdos e os profissionais que trabalham com as manifestações de expressividade corporal afrobaianas, a Capoeira Angola e a Dança Afro podem ser incorporada ao sistema e programas de ensino em escolas e universidades, na perspectiva de contribuírem para uma educação multicultural (Conrado, 2006, p. 20).

[...] qual era a metodologia de ensino e a ação pedagógica que usava Mestre Bimba para ensinar a Capoeira Regional e quais seus desdobramentos na formação educacional, cultural e de filosofia de vida dos seus alunos? (Campos, 2006, p. 25).

\footnotetext{
${ }^{7} \mathrm{O}$ período em destaque diz respeito à defesa da primeira e última tese, até o ano em que ingressamos no Mestrado.
} 
Seja do contexto de crítica à racionalidade moderna (Abib, 2004), a necessidade de implementação de uma ação coletiva e afirmativa em prol da mobilidade social positiva e a eliminação do preconceito racial e da discriminação (Conrado, 2006), ou ainda a possibilidade de interferir no processo educacional com valores da cultura afro-brasileira (Campos, 2006), ambos os problemas de pesquisa derivam duma matriz epistemológica sedimentada em práticas corporais contra-hegemônicas, em particular a capoeira.

Os principais objetivos das pesquisas, apresentados pelos autores no desenrolar de suas teses, reiteram esta hipótese, tendo em vista suscitarem a necessidade de análise dos processos inerentes às práticas da "cultura corporal negra" e as possibilidades de contribuição na formação educacional por meio destas.

[...] analisar os processos educativos não-formais presentes na capoeira angola, no sentido de levantarmos alguns aspectos importantes desses processos. Estamos buscando assim, inspiração nas formas tradicionais de ensinar-aprender utilizadas nesse universo, sobretudo a partir das influências marcantes da cultura afro-brasileira, que caracterizam decisivamente as manifestações da cultura popular [...] para refletirmos sobre outros modelos de aprendizagem possíveis (Abib, 2004, p. 121-122).

[...] estudar como os saberes das manifestações da expressividade corporal negra na Bahia, a Capoeira Angola, a Dança Afro e os profissionais dessas culturas podem contribuir para uma educação multicultural na direção de políticas públicas em gestão de participação democrática (Conrado, 2006, p. 20).

Analisar a metodologia que usava Mestre Bimba para ensinar a Capoeira Regional e seus desdobramentos decorrentes da ação pedagógica quanto à formação educacional, cultural e de filosofia de vida dos seus alunos (Campos, 2006, p. 25).

Outro item observado, que corrobora no sentido da consolidação de novos caminhos para a prática da pesquisa na área, superando as abordagens metodológicas empírico-analíticas, diz respeito aos procedimentos relativos ao tipo de pesquisa desenvolvida pelos autores. Quanto a esta questão, observamos que Abib (2004) utilizou-se principalmente da metodologia da História Oral; enquanto Conrado serviu-se da pesquisa participante, da 
pesquisa-ação e da etnometodologia; e Campos (2006) utilizou-se sobremaneira das estratégias das pesquisas histórica, descritiva, biográfica e antropológica.

[...] estamos nos utilizando da metodologia da História Oral, como estratégia de reconstruir esse universo da capoeira angola a partir do imaginário e da memória dos capoeiras baianos (Abib, 2004, p. 83).

O caminho da pesquisa e da construção da tese se deu pela apropriação de recursos e procedimentos metodológicos da pesquisa participante (Brandão, 1986); da pesquisa-ação (Thiollent, 1981; 1980) e da etnometodologia (Coulon, 1995), porque servem para apreensão de fenômenos sociais oriundos de questões e de sujeitos que pouco são tratados pela ciência de modo geral, motivo de minha afinidade e opção (Conrado, 2006, p. 63).

Esta pesquisa é de natureza qualitativa participante e tem as características de um estudo histórico, descritivo, biográfico e antropológico (Campos, 2006, p. 124).

Outro indicador observado que contribui com o entendimento da possível ascensão duma abordagem de pesquisa para a nossa área, referendada no contexto histórico-cultural da população afro-descendente foi o local onde foram coletados os dados/informações produzidos nas pesquisas empíricas pelos pesquisadores. Ambas as teses tiveram como lócus de pesquisa a realidade do estado da Bahia, e em especial a cidade de Salvador ${ }^{8}$.

[...] contamos com a privilegiada contribuição de alguns dos velhos mestres de capoeira da Bahia, que vêm emprestar suas vozes, sua sabedoria e suas visões de mundo, e amparar-nos nessa delicada tarefa de interpretar os sentidos e os significados dessa manifestação (Abib, 2004, p. 07).

[...] pessoas que trabalham na cidade de Salvador, estado da Bahia, no ensino-aprendizagem da Capoeira Angola e da Dança Afro (Conrado, 2006, p. 25).

Verificamos ainda que, devido à necessidade de "dar voz" aos sujeitos que constituem essa realidade, ou seja, mestres, contramestres, professores e alunos, engajados em processos de formação cuja característica é o

\footnotetext{
${ }^{8}$ Apesar de não explicitar o local da coleta de dados, é provável que Hélio Campos também tenha realizado sua coleta na cidade de Salvador-BA, se observarmos, por exemplo, quem foram os entrevistados pelo autor.
} 
desenvolvimento da "cultura física negra", as fontes utilizadas para a coleta de dados foram:

[...] depoimentos orais coletados de velhos mestres ainda em atividade na cena capoeirística da Bahia, bem como de alguns capoeiras comuns, atores dessa expressão cultural. Valemo-nos também, de manuscritos deixados por mestres já falecidos, de relatos orais transcritos por outros pesquisadores, da análise das músicas cantadas nas rodas de capoeira, da poesia e da literatura, das histórias e dos personagens que habitam o imaginário coletivo dos capoeiras, e da nossa própria vivência no universo da capoeiragem baiana (Abib, 2004, p. 83).

[...] opto como sujeitos desta pesquisa, pessoas que trabalham na cidade de Salvador, estado da Bahia, no ensino-aprendizagem da Capoeira Angola e da Dança Afro (Conrado, 2006, p. 25).

A população amostra foi composta de 15 ex-alunos de Mestre Bimba, com passagem marcante dentro do CCFR, que na atualidade atuam ou não como mestres ensinando a Capoeira Regional. O critério de inclusão baseou-se no envolvimento e contribuição dos sujeitos no processo de expansão da Capoeira Regional, por terem sido indivíduos ativos na academia e fora dela e que tenham no mínimo 20 anos de vivência prática e estudos contínuos na área da capoeira (Campos, 2006, p. 128).

A outra amostra foi composta de 16 mestres, contramestres e professores de capoeira contemporâneos. $O$ critério de inclusão usado foi: (a) não ter sido aluno de Mestre Bimba; (b) estar ministrando aulas de capoeira em escolas, universidades, academias ou grupos; (c) ter publicação na área; e (d) estar ativo, participando efetivamente dos movimentos capoeirísticos, batizados, formaturas, cursos, seminários, debates etc. Essa amostra foi escolhida numa relação de quarenta e-mails de um banco de dados do pesquisador não sendo levado em conta o estilo de capoeira, se angola e regional (Campos, 2006, p. 128).

Ao analisar as fontes utilizadas por estes autores para a realização das pesquisas evidenciamos um reconhecimento maior para com os sujeitos, mestres, professores, pesquisadores que dedicam suas vidas à reprodução/produção da cultura (material e imaterial) alicerçada na realidade das camadas populares, assim como a necessidade de compreensão dos saberes produzidos nestas relações de forma mais aprofundada e a possibilidade de entendimento de outros processos pedagógicos que historicamente vêm sendo construídos por estes sujeitos, mas ainda desvalorizados pelas instituições de ensino formal em nosso país.

Por outro lado, no que diz respeito às técnicas de coleta de dados/informações utilizadas nas teses, é interessante observar a 
possibilidade de se pesquisar, tendo como referência outras formas de se construir conhecimento, que evidenciam a necessidade de se repensar as relações estabelecidas na prática da pesquisa em nossa área, neste caso, valorizando técnicas qualitativas que nos aproximem ainda mais da realidade das culturas tradicionais. Além disso, a ruptura com as técnicas que preconizam a separação entre sujeito e objeto do conhecimento, derivadas do paradigma positivista, é superada com estratégias em que prevalecem à interação entre os sujeitos produtores de conhecimento.

[...] o relato oral está na base da obtenção de toda sorte de informações e antecede outras técnicas de obtenção e conservação do saber (Abib, 2004, p.84).

[...] fiz opção pelos seguintes métodos de coleta de dados [...] O acompanhamento e participação em aulas, reuniões, atividades na Escola de Capoeira Angola (ECAIG) e Grupo de Dança do Ilê Aiyê, para aulas, ensaios, conversas, entrevistas, troca de serviços, reuniões conjuntas [...] (Conrado, 2006, p. 68).

Os dados [...] foram coletados através da observação participante em eventos de capoeira previamente selecionados. Destacamos os seminários, debates, reuniões com os alunos de Bimba, na Fundação Mestres Bimba, batizados e rodas de capoeira (Campos, 2006, p. 132).

Com relação às possibilidades de interpretação dos dados, a partir duma perspectiva epistemológica de reorientação das pesquisas que tomam como objeto de estudo práticas corporais desenvolvidas historicamente pelos povos afro-brasileiros, verificamos que os autores têm buscado aprofundar teorias, sobretudo do campo das ciências humanas / sociais, que contribuam para uma maior compreensão da lógica que perpassa o discurso dos sujeitos envolvidos nestas práticas e dos fundamentos do conhecimento transmitido nos processos pedagógicas protagonizados por estes sujeitos.

Acreditamos ser possível uma elaboração teórica que possa abrir perspectivas para uma maior subjetivação e alargamento da racionalidade que orienta as sociedades modernas, para que seja possível a apreensão desses saberes e dessa lógica diferenciada. Por isso, buscaremos basear-nos no argumento que já vem sendo elaborado por alguns autores no campo das ciências sociais, que visam a dar conta dessa tarefa (Abib, 2004, p. 65-66).

Através da reconstituição do percurso histórico [...], busco fazer conexões, para compreensão de uma epistemologia educacional de contraposição, 
elegendo a abordagem Multicultural, pelas características que possuem no nível de sua proposta, redimensionada e atualizada, conforme os contextos que expressam diferentes conceitos, valores e pensamentos de educação (Conrado, 2006, p. 78).

A Análise e Interpretação dos Dados foi realizada através da técnica de análise de conteúdo [...]. Escolhemos essa técnica por entender ser a que mais atenderia ao nosso estudo, justamente por poder compreender criticamente os sentidos das comunicações, seu conteúdo manifesto ou latente e as significações explícitas ou ocultas (Campos, 2006, p. 28).

Apresentada esta síntese, dentro dos limites de nossa compreensão, cabe agora retomar as referências que têm orientado nossas aproximações do debate próprio do campo epistemológico para orientar algumas análises sobre nosso objeto de estudo.

\section{O processo de (re)orientação teórico-epistemológica do departamento III - FACED/UFBA}

De posse das teses (Abib, 2004; Conrado, 2006; Campos, 2006), por meio das questões definidas no processo de coleta de dados/informações, realizamos uma primeira análise da estrutura interna, ou da lógica da pesquisa, buscando reconhecer possibilidades de uma abordagem de pesquisa que contribua para a construção de uma prática pedagógica na educação física que toma como objeto a cultura corporal negra no estado da Bahia.

Os dados encontrados parecem corroborar o entendimento da (re)construção deste paradigma em nossa área. Pois, a análise dos modelos de pesquisa tem apontado no sentido da superação das abordagens descontextualizadas.

O professor Pedro Abib (2004), por exemplo, critica determinada racionalidade moderna, especificamente nas categorias de análise que não dão conta de explicar processos de conhecimento que ocorrem na roda de capoeira, recorrendo a categorias - ritualidade, ancestralidade, temporalidade - desenvolvidas por cientistas sociais que buscam responder às questões elaboradas em torno das necessidades duma racionalidade diferenciada. 
A professora Amélia Conrado (2006), por sua vez, trabalhando com uma metodologia já consagrada no campo das ciências sociais (pesquisaação), apresenta resultados concretos dum plano de ação desenvolvido durante a pesquisa, a saber: elaboração e inscrição e aprovação do "Projeto Capoeira Angola: instrumento de educação, cidadania e identidade cultural" junto ao Ministério da Cultura; e aprovação e implantação do Projeto "Aulas de Capoeira Angola na Escola Municipal Vivaldo Costa Lima" na Secretaria Municipal de Educação e Cultura (SMEC Salvador-BA), contribuindo sobremaneira para a revalorização da cultura afro-brasileira.

Quanto ao professor Helio Campos (2006), a abordagem biográfica desenvolvida pelo autor parece um elemento de fundamental importância para a preservação da memória dos sujeitos que produziram as denominadas culturas de resistência, ou mesmo para (re)contar a história destes sujeitos, sobretudo aqueles que já não estão entre nós fisicamente, na medida em que contemplou o sujeito compreendido e comprometido com seu tempo, com seus semelhantes.

Dessa maneira, a necessidade de redefinição dos pressupostos que orientam a pesquisa na área - como vimos nesta amostra - visando à revalorização de aspectos da nossa cultura parece de fundamental importância para a construção de uma abordagem mais significativa para a prática pesquisa no campo da educação física no estado da Bahia.

Nesse sentido, o modelo epistemológico desenvolvido a partir de Habermas (1982) parece contribuir decisivamente neste aspecto, por destacar a necessidade de compreendermos as relações subjacentes ao desenvolvimento dos métodos de pesquisa e motivações que orientam as ações humanas.

A partir da análise das teses é possível dizer que as abordagens utilizadas estão voltadas para questões relativas à compreensão da capoeira em sua diversidade, isto é, aproximando-se menos do campo técnico e mais dos campos prático/emancipatório, talvez em virtude de outras possibilidades de produção do conhecimento contemporâneas (pósmodernismo, multirreferencialidade etc). 
Sabemos que o diálogo entre a educação física e as ciências humanas / sociais, em particular com as "ciências da educação", em nível de pós graduação, no Brasil, vem se desenvolvendo desde a década de 1980 (Bracht, 1999). Porém, passados aproximadamente 30 anos das primeiras incursões, na denominada sub-área sociocultural, talvez atualmente os interesses dos pesquisadores não sejam mais "buscar reconhecimento acadêmico e profisssional para a educação física" e sim reconhecer fundamentos políticos, éticos e epistemológicos e possibilidades de intervenção no campo educacional - formal e não formal - através das formas de manifestação da cultura corporal afro-descendente.

Entretanto, os modelos epistemológicos que utilizamos como referência em nosso estudo apresentaram limites na compreensão de categorias emergentes desta visão de mundo (tais como ancestralidade, memória, ritualidade etc) que poderão ser ultrapassados por uma epistemologia contemporânea de sustentação para esta matriz.

\section{Considerações finais}

Em síntese, procuramos evidenciar o nexo entre o conjunto das abordagens utilizadas nas teses analisadas e interesses humanos subjacentes a esta produção. Habermas (1982) fornece um modelo que permite redescobrir por debaixo de determinadas epistemologias a raiz internacional entre os participantes em determinada ação.

No caso da capoeira, um fenômeno cultural que surge para preservar a identidade cultural dos povos afro-descendentes e lidar com situações de injustiça social, parece que como vem sendo abordada pode favorecer aos projetos educacionais de emancipação humana.

Dessa maneira, as abordagens mais recente evidenciam indicadores dum possível processo de (re)orientação da pesquisa e produção do conhecimento no campo da educação física no estado da Bahia, a partir do diálogo com a cultura dos povos afro-descendentes. 


\section{Referências}

ABIB, P. R. J. Capoeira angola: cultura popular e o jogo dos saberes na roda. 2004. Tese (Doutorado em ciências sociais aplicadas à educação). Universidade Estadual de Campinas, Campinas.

BRACHT, V. Educação física \& ciência: cenas de um casamento (in) feliz. Ijuí: Unijuí, 1999 (Coleção Educação Física).

CAMPOS, H. J. B. C. de. Capoeira regional: a escola de Mestre Bimba. 2006. Tese (Doutorado em Educação), Universidade Federal da Bahia, Salvador.

CONRADO, A. V. de S. Capoeira angola e dança afro: contribuições para uma política de educação multicultural na Bahia. 2006. Tese (Doutorado em educação), Universidade Federal da Bahia, Salvador.

FENSTERSEIFER, P. E. A crise da racionalidade moderna e a educação física. in: Revista Brasileira de Ciências do Esporte. (Epistemologia e educação física). V. 22, n. 1, p. 7 - 126, setembro de 2000. Campinas: Autores Associados.

FERraro, A. A educação Física na Babia: Memórias de um professor. EDUFBA, Salvador; 1991.

GEUSS, Raymond. Teoria crítica: Habermas e a Escola de Frankfurt. Tradução Bento Itamar Borges. Campinas, SP: Papirus, 1988.

HABERMAS, J. Conhecimento e Interesse. Rio de Janeiro: Zahar, 1982.

HABERMAS, J. Conhecimento e Interesse. In: Técnica e ciência como "ideologia". Lisboa: Edições 70. s.d., p. 129-147.

ROSSO, S. Centro de Educação Física e esportes da UFBA: centro de formação de professores da cultura corporal - realidade e possibilidades. Dissertação (Mestrado). Faculdade de Educação, Universidade Federal da Bahia, Salvador, 2007.

SANCHEZ GAMBOA, S. Á. Epistemologia da Pesquisa em Educação: estruturas lógicas e tendências metodológicas. 1987. Tese (Doutorado em Educação). UNICAMP, Campinas.

SÁNCHEZ GAMBOA, S. Á. et al. A pesquisa em educação física no nordeste brasileiro (Alagoas Bahia, Pernambuco e Sergipe), 1982-2004: balanço e perspectivas. In: Revista Brasileira de Ciências do Esporte, Campinas, v. 29, n. 1, p. 89-106, set. 2007. 
SILVA, R. V. de S. Pesquisa em educação física: determinações históricas e implicações epistemológicas. 1997. Tese (Doutorado em Educação), UNICAMP, Campinas. 